\title{
New Approach in the Energy Analysis of an NH3-NaSCN Single Effect Absorption Machine (SEAM) with a Counter-Current Coaxial Tubes Internal Heat Exchanger (3CT-IHE)
}

\author{
O.T. Sosso Mayi ${ }^{1, *}$, J.P. Njock ${ }^{1}$ and M.K. Ndame ${ }^{2}$ \\ ${ }^{1}$ Department of Electrical Engineering, ENSET of Douala University, Cameroon, BP 1872 Douala, Cameroon \\ ${ }^{2}$ Department of Energy and Thermal Engineering, IUT of Douala University, Cameroon, BP 8698 Douala, \\ Cameroon
}

\section{Article Info:}

Keywords:

Energy analysis,

Thermal behavior,

Counter-current heat recovery

exchanger,

Single effect absorption machine,

Thermal efficiency.

\section{Timeline:}

Received: September 29, 2021

Accepted: November 05, 2021

Published: November 11, 2021

Citation: Sosso Mayi OT, Njock JP, Ndame MK. New Approach in the Energy Analysis of an NH3-NaSCN SingleEffect Absorption Machine (SEAM) with a Counter-Current Coaxial Tubes Internal Heat Exchanger (3CTIHE). J Basic Appl Sci 2021; 17: 168183.

\begin{abstract}
:
Energy analysis provides the ability to assess performance and determine the size of equipment in a system. However, precisely integrating the thermal behavior of the component equipment makes it possible to better assess the performance of the system. This work highlights the influence of the thermal behavior of a 3CT-IHE on the performance and size of the equipment of SEAM with NH3-NaSCN as a working fluid. Based on equations of conservation balances of mass, species and energy, the energy analysis made showed that depending on the magnitude of the heat flows of the weak and strong solutions involved in the heat exchange at the level of the 3CT-IHE, there are different temperature ranges for which the weak solution or the strong solution governs the heat transfer, thus giving rise to the notions of "thermal heating efficiency" and "thermal cooling efficiency" respectively. The results obtained were compared with those of Sun. This new approach has demonstrated better performance of the SEAM for the same operating conditions. It has also been shown that it is possible to increase the temperature of the generator above $90{ }^{\circ} \mathrm{C}$ without resorting to another working fluid and that in the case of subjecting $\mathrm{NH} 3-\mathrm{NaSCN}$ to supercritical conditions in temperature at the generator; it is possible to obtain a machine COP greater than 1 and an even smaller pump size.
\end{abstract}

*Corresponding Author

E-mail: O_SOSSO@yahoo.fr

(C) 2021 Mayi et al.; Licensee SET Publisher.

This is an open access article licensed under the terms of the Creative Commons Attribution Non-Commercial License (http://creativecommons.org/licenses/by-nc/3.0/) which permits unrestricted, non-commercial use, distribution and reproduction in any medium, provided the work is properly cited. 


\section{INTRODUCTION}

Absorption machines present themselves nowadays as an alternative in reducing both the consumption of electrical energy [1, 2] and environmental pollution [3]. Appropriate technologies for residential cooling applications [4], they find their interest in their potential to recover residual energies at low temperatures $[5,6]$; which makes them very attractive systems [6], viable and economical. However, the disadvantage of these machines is their large size for a coefficient of performance generally below $0.7[7,8]$ for the single effect absorption machine and 1.5 [9] for the double effect absorption machine. In recent years, many studies have been carried out aimed at improving the performance of absorption machines. Beyond techniques for optimizing the stability and photothermal conversion performance of solar generators [10], operation under adiabatic conditions of the absorber [11] or finding the right mix of fluids for absorption machines [12,13], it is obvious to observe the use of a thermal regenerator internal heat exchanger between the circulation lines of the so-called weak and strong solutions. The application of such an energy efficiency approach, in order to guarantee an accurate evaluation of the performance of the absorption machine, requires a good approach in the thermal characterization of the internal heat exchanger; which is generally carried out by evaluating its thermal efficiency.

In his numerous works on heat transfers and more particularly on heat exchangers, the Ref. [14] indicated that for the operation of a counter-current heat exchanger, two cases can be distinguished depending on the magnitudes of the heat flows of the two fluids involved in the heat exchange, thus giving rise to the concept of "fluid which controls heat transfer" and indirectly to the notions of "thermal efficiency of heating" and "thermal efficiency of cooling". The term noted calorific flow $q_{c}\left(W /{ }^{\circ} \mathrm{C}\right)$ is thus understood to mean the product of the mass flow $q_{m}(\mathrm{~kg} / \mathrm{s})$ of a fluid and its specific heat capacity $C_{p}\left(J / k g /{ }^{\circ} \mathrm{C}\right)$. Thus, knowledge of both the mass thermal flow rates and capacities of the fluids involved in the heat exchange process at the level of the thermal regenerator allows an evaluation of the magnitudes of the heat flows and by comparison, to define the type of thermal efficiency resulting.

Many studies calculate the efficiency of the thermal regenerator without taking into account the concept of "fluid that controls the heat transfer", thus limiting themselves to the calculation of the heating efficiency; which can give rise to an underestimation or an overestimation of the performance of the absorption machine. The Ref. [2] carried out the comparative study of $\mathrm{NH}_{3}-\mathrm{NaSCN}, \mathrm{NH}_{3}-\mathrm{H}_{2} \mathrm{O}$ and $\mathrm{NH}_{3}-\mathrm{LiNO}_{3}$ fluids in order to determine the ideal binary fluid for the high-performance operation of a SEAM. The efficiency of the exchanger was calculated by considering the strong solution coming from the generator as the fluid which controls the heat transfer. The results presented a limit in the performance and operation of the absorption machine. The Ref. [15] investigated a similar study and more recently the studies of the Ref. $[16,17,18]$. To thermally characterize the thermal regenerator,the Ref. [19] carried out a report of the temperatures operating at the level of this component. It is clear that to a lesser extent the concept of "fluid which controls heat transfer" is applied. But the author does not indicate anywhere, the approach in the evaluation of the heat flows of the different fluids. The thermal efficiency of the exchanger was defined among the various assumptions; which conditions the knowledge of the heat flows for the determination of the type of efficiency and therefore the calculation of the temperatures at the level of the heat exchanger.

The aim of this work is to highlight the impact of the concept of "fluid which controls heat transfer" in the performance evaluation of systems incorporating a counter-current heat exchanger as a heat regenerator. It is aimed for us, to bring our contribution to the understanding of the limitation of the operating conditions in terms of the operating temperature ranges of absorption machines.

\section{DESCRIPTION OF THE SYSTEM}

The system studied is a single-effect refrigeration machine (SEAM) with a binary ammonia-sodium thiocyanate $\left(\mathrm{NH}_{3}-\mathrm{NaSCN}\right)$ as illustrated in Figure 1. This system and its binary pair were chosen in relation to the availability of data facilitating a comparative study. The system integrates both a generator (1-7-8), a condenser (1-2), an evaporator (3-4), an absorber (4$5-10)$, a thermal regenerator (6-7- 8-9), a cold regulator (2-3), a pump (5-6) and a hot regulator (9-10). As in mechanical compression machines, the system consists of a high-pressure circuit and a low-pressure circuit. Depending on the ammonia concentration in the binary mixture, there are three lines in the system, in particular: (i) the line with pure solution (1-2-3-4), (ii) the poor solution line (5-6-7) and (iii) the strong solution line (8-9-10). Thus, according to the definition of ASHRAE as described by the Ref. [2], a weak solution is understood to mean the solution having a low capacity to absorb refrigerant vapor.

In its principle of operation, with the supply of heat $Q_{g}$, the $\mathrm{NH}_{3}$ refrigerant in the weak solution vaporizes in 


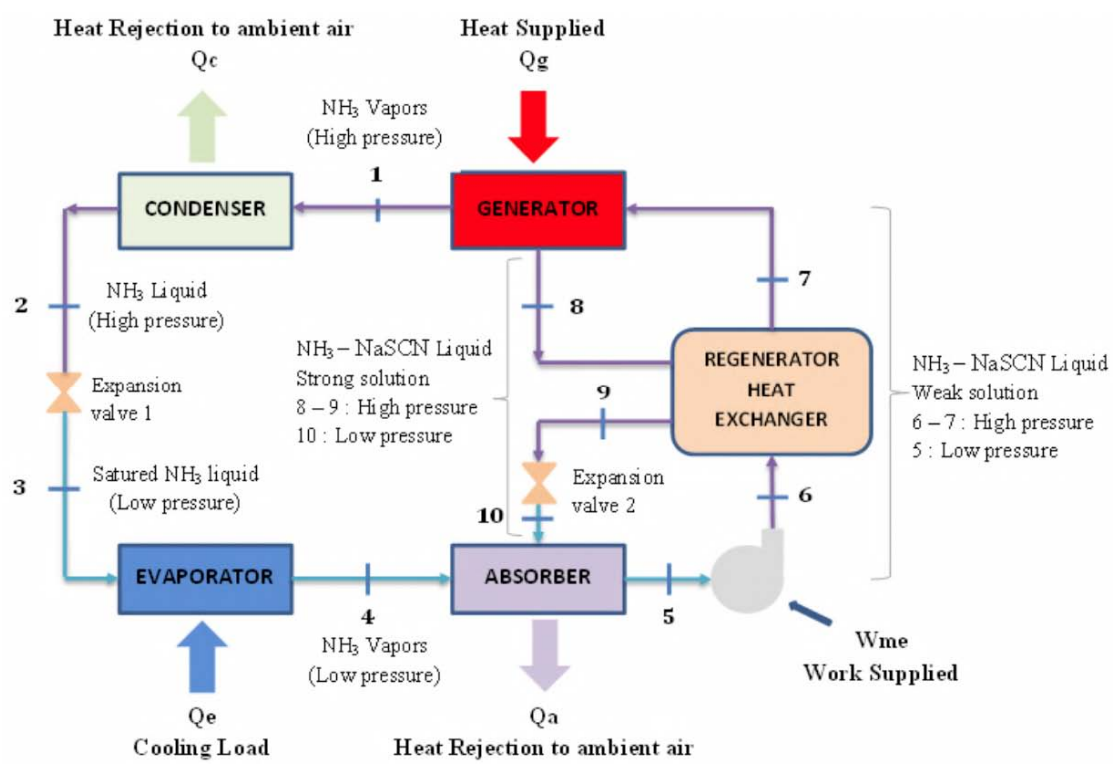

Figure 1: The schematic of the Single Effect Absorption Machine (SEAM).

the generator (1). The pure refrigerant vapor cools and liquefies at high pressure (2) in the condenser and then passes into the evaporator (4) through an expansion valve (3) which reduces the pressure of the refrigerant to the low pressure existing in the evaporator. The liquid refrigerant admitted to the evaporator vaporizes by absorbing the heat from the enclosure to be cooled and the resulting vapor under low pressure (4) passes into the absorber. After vaporization of the pure refrigerant in the generator, the solution remaining in the mixture, also called strong solution (8), arrives at the absorber through a heat recovery exchanger (9) and a pressure reducing valve (10) where it absorbs the vapors (4) produced in the evaporator to form the weak solution (5). The weak solution (5) is then pumped at high pressure (6) to the generator through a heat recovery exchanger where it absorbs part of the calories of the strong solution. Once the weak solution has been preheated (7), it is admitted into the generator to give rise to a new cycle.

\section{THERMODYNAMIC ANALYSIS}

\subsection{Hypotheses}

1. The system operates in a state of equilibrium.

2. Energy losses and pressure drop along the system piping are negligible.

3. The $\mathrm{NH}_{3}-\mathrm{NaSCN}$ solution is respectively in the state of equilibrium at the level of the generator and of the absorber.

4. The pure ammonia is in the saturated state respectively at the level of the evaporator and the condenser.
5. The kinetic and potential energies of the system are negligible.

\subsection{Mathematical Formulations}

The performance of the absorption refrigeration cycle is determined by calculating the operational coefficient of performance (COP) as follows:

$C O P=\frac{\dot{Q} e}{\dot{W}_{m e}+\dot{Q}_{g}}$

The use of equation (1) is made by establishing the mass and energy balance equations following a phenomenological approach to thermodynamics. Elaborated on the basis of the hypotheses formulated and from equations (2), (3) and (4) respectively reflecting the mass, material and energy balances, Table 1 summarizes the different equations established at the level of each component of the system $[2,5]$.

Total mass balance:

$\sum \dot{m}_{i}=0$

Material balance:

$\sum X_{i} \dot{m}_{i}=0$

Energy balance:

$\sum \dot{Q}_{i}+\sum \dot{W}_{i}+\sum \dot{m}_{i} h_{i}=0$

Table 1 respectively associates the flow rates of the strong and weak solutions and the rate of circulation of 
Table 1: Mass / Material / Energy equations for different components of SEAM

\begin{tabular}{|c|c|}
\hline Component & Mass / Material / Energy equations \\
\hline $\mathrm{NH}_{3}-\mathrm{NaSCN}$ Generator & $\begin{array}{l}\dot{m}_{7}=\dot{m}_{1}+\dot{m}_{8} \\
\dot{m}_{7} X_{7}=\dot{m}_{1} X_{1}+\dot{m}_{8} X_{8} \\
\dot{Q}_{g}=\dot{m}_{1} h_{1}+\dot{m}_{8} h_{8}-\dot{m}_{7} h_{7}\end{array}$ \\
\hline $\mathrm{NH}_{3}$ Condenser & $\begin{aligned} \dot{m}_{2} & =\dot{m}_{1}(8) \\
X_{2} & =X_{1}(9) \\
\dot{Q}_{c} & =\dot{m}_{1}\left(h_{1}-h_{2}\right)(10)\end{aligned}$ \\
\hline $\mathrm{NH}_{3}$ Expansion Valve 1 & $\begin{array}{l}\dot{m}_{3}=\dot{m}_{2}(11) \\
X_{3}=X_{2}(12) \\
h_{3}=h_{2}(13)\end{array}$ \\
\hline $\mathrm{NH}_{3}$ Evaporator & $\begin{aligned} \dot{m}_{4} & =\dot{m}_{4}(14) \\
X_{4} & =X_{3}(15) \\
\dot{Q}_{e} & =\dot{m}_{1}\left(h_{4}-h_{3}\right)(16)\end{aligned}$ \\
\hline $\mathrm{NH}_{3}-\mathrm{NaSCN}$ Absorber & $\begin{array}{l}\dot{m}_{5}=\dot{m}_{4}+\dot{m}_{10} \\
\dot{m}_{5} X_{5}=\dot{m}_{4} X_{4}+\dot{m}_{10} X_{10} \\
\dot{Q}_{a}=\dot{m}_{4} h_{4}+\dot{m}_{10} h_{10}-\dot{m}_{5} h_{5}\end{array}$ \\
\hline $\mathrm{NH}_{3}-\mathrm{NaSCN}$ Pump & $\begin{array}{l}\dot{m}_{6}=\dot{m}_{5}(20) \\
X_{6}=X_{5}(21) \\
\dot{W}_{m e}=h_{6}-h_{5}(22) \\
\dot{W}_{m e}=\left(P_{6}-P_{5}\right) \times v_{6}(23)\end{array}$ \\
\hline $\mathrm{NH}_{3}-\mathrm{NaSCN}$ Expansion Valve 2 & $\begin{array}{l}\dot{m}_{10}=\dot{m}_{9}(24) \\
X_{10}=X_{9}(25) \\
h_{10}-h_{9}(26)\end{array}$ \\
\hline $\mathrm{NH}_{3}-\mathrm{NaSCN}$ Regenerator Heat Exchanger & $\begin{array}{l}\dot{m}_{7}=\dot{m}_{6}(27) \\
X_{7}=X_{6}(28) \\
\dot{m}_{9}=\dot{m}_{8}(29) \\
X_{9}=X_{8}(30) \\
\dot{m}_{6}\left(h_{7}-h_{6}\right)=\dot{m}_{8}\left(h_{8}-h_{9}\right)(31)\end{array}$ \\
\hline
\end{tabular}

the weak solution as a function of the pure solution as follows:

$\dot{m}_{8}=\frac{X_{1}-X_{7}}{X_{7}-X_{8}} \dot{m}_{1}$

$\dot{m}_{7}=\frac{X_{1}-X_{8}}{X_{7}-X_{8}} \dot{m}_{1}$

$\tau_{c}=\frac{\dot{m}_{7}}{\dot{m}_{1}}$

\section{CONCEPT OF "FLUID THAT CONTROLS HEAT TRANSFER"}

The thermal efficiency of the thermal regenerator is defined in accordance with the concept of "fluid which controls heat transfer". This concept as described by the Ref. [14], implies that for the operation of a heat exchanger against the current, the temperature distribution in the exchanger is a function of the fluid that governs the heat transfer. The term "fluid which governs the transfer of heat" is understood to mean the fluid whose heat flow $q_{c}\left(\mathrm{~J} /{ }^{\circ} \mathrm{C} / s\right)$ is low. It can therefore be the hot fluid or the cold fluid. The heat flow of a fluid is the product of its mass flow $q_{m}(\mathrm{~kg} / \mathrm{s})$ to its specific heat capacity $C_{p}\left(\mathrm{~J} / \mathrm{kg} /{ }^{\circ} \mathrm{C}\right)$. That is:

$q_{c}=\dot{m} \times C_{p}$

Thus, for a heat exchanger with counter-current coaxial tubes as illustrated in Figure 2, the temperature distribution presents one of the forms illustrated in Figure 3.

$T_{c e}$ and $T_{C S} \quad\left(T_{f e}\right.$ and $\left.T_{f s}\right)$ respectively represent the inlet and outlet temperatures of the hot (cold) fluid expressed in ${ }^{\circ} \mathrm{C}$. 


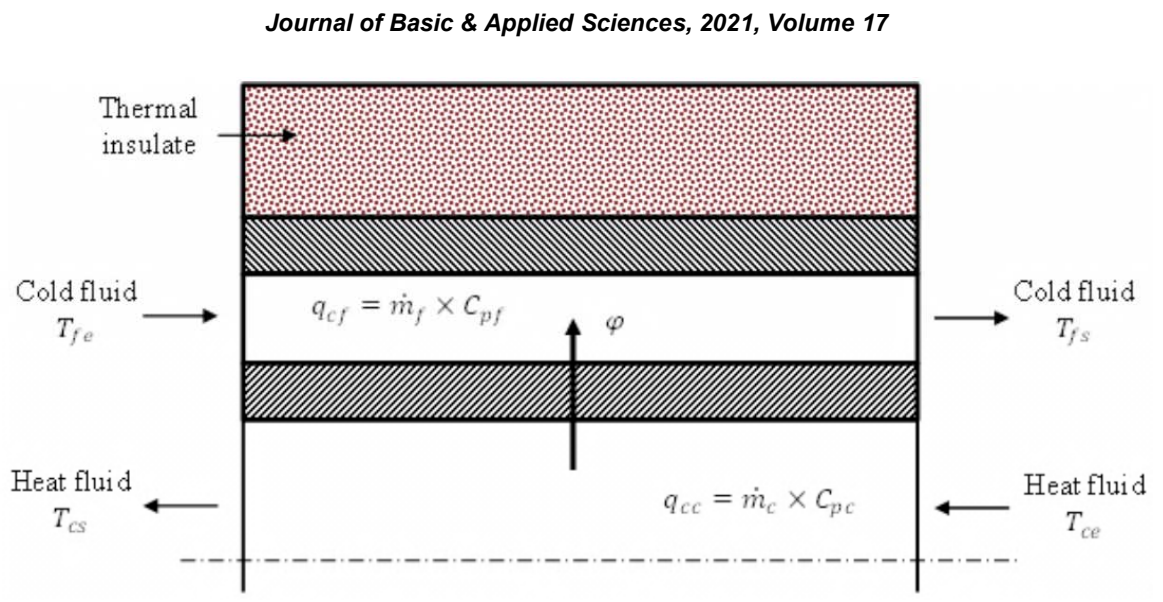

Figure 2: The schematic of counter-current heat exchanger.

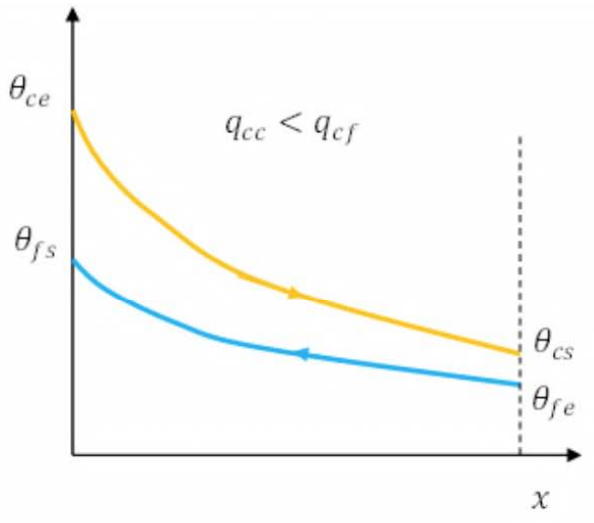

(a)

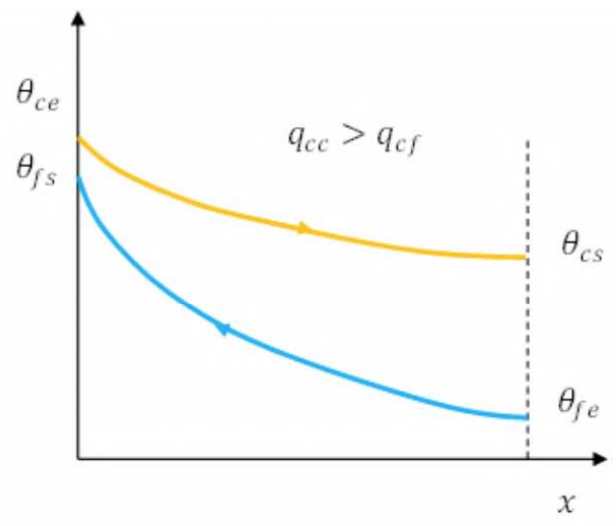

(b)

Figure 3: Temperature evolution in a countercurrent heat exchanger (a): the strong solution controls the heat transfer, (b): the weak solution controls the heat transfer.

The thermal efficiency of the heat exchanger is defined as the ratio of the heat flow actually transferred in the exchanger to the maximum heat flow that would be transferred under the same conditions of inlet temperatures of the two fluids in a tubular exchanger of infinite length working against the current [14]:

$\eta_{t h, e x}=\frac{\Phi}{\Phi_{\max }}$

Figure 3 illustrates two scenarios:

- If $q_{c c}<q_{c f}$, we say that the "hot fluid controls the heat transfer". In this case, the "thermal cooling efficiency" of the exchanger is defined:

$\eta_{t h, e x r}=\frac{T_{c e}-T_{C S}}{T_{c e}-T_{f e}}$

- If $q_{c c}>q_{c f}$, we say that the "cold fluid controls the transfer of heat". In this case, the "thermal heating efficiency" of the exchanger is defined: $\eta_{t h, e x r}=\frac{T_{f s}-T_{f e}}{T_{c e}-T_{f e}}$

\section{CHOICE OF WORKING FLUID}

Absorption refrigeration systems using working fluids $\mathrm{NH}_{3}-\mathrm{LiBr}$ and $\mathrm{NH}_{3}-\mathrm{H}_{2} \mathrm{O}$ have known a limitation in their application due to many drawbacks such as crystallization, corrosion, toxicity, rectification, etc. [20, 21]. Numerous works indicate binary mixing $\mathrm{NH}_{3}-\mathrm{NaSCN}$ as an alternative in improving the performance of an absorption refrigeration system; we can list for this purpose, [22, 23]. In the context of our study, we will consider the $\mathrm{NH}_{3}-\mathrm{NaSCN}$ mixture as a working fluid.

\subsection{Thermodynamic Properties of the Chosen Working Fluid}

In our $\mathrm{NH}_{3}-\mathrm{NaSCN}$ binary mixture absorption refrigeration cycle, the thermodynamic properties in states (1) - (4) are defined by the pure solution (NH3), those in states (5) - (7) are defined by the weak 
solution ( $\mathrm{NH}_{3}-\mathrm{NaSCN}$ ) and those in states (8) - (10) are defined by the strong solution $\left(\mathrm{NH}_{3}-\mathrm{NaSCN}\right)$. Given that it is accepted that the performance of absorption cycles strongly depends on the chemical and thermodynamic properties of the refrigerant/absorbent pair used; such as thermal stability, heat capacity, volatility and chemical solubility [24], the determination of the specific heat capacity, therefore, appears to be a necessity.

The Ref. [21] studied the thermodynamic and physical properties of the $\mathrm{NH}_{3}-\mathrm{NaSCN}$ binary couple. Empirical correlations of the thermodynamic properties of $\mathrm{NH}_{3}-\mathrm{NaSCN}$ having been defined, like the specific enthalpies in vapor and liquid phase, of the specific volume and more particularly the specific heat capacity necessary for the calculation of the heat flow. The Ref. $[4,25]$ provide the properties in saturated and superheated states of vapor and liquid ammonia.

\subsubsection{Pure Solution $\mathrm{NH}_{3}$}

In the pressure and temperature ranges typical for refrigeration applications, the pressure and the saturated temperature of the $\mathrm{NH}_{3}$ refrigerant are related by the relationship:

$$
P(T)=10^{3} \sum_{i=0}^{6} a_{i} T^{i}
$$

The specific enthalpies of saturated liquid and vapor are expressed as a function of temperature as follows: $\mathrm{NH}_{3}$

$h_{L}(T)=\sum_{i=0}^{6} b_{i} T^{i}$

$h_{V}(T)=\sum_{i=0}^{6} c_{i} T^{i}$

Empirical coefficients $a_{i}, b_{i}$ and $c_{i}$ are listed in Table 2 [2].

\subsubsection{Binary Mixture $\mathrm{NH}_{3}-\mathrm{NaSCN}$}

The relationship between pressure, concentration $X_{\mathrm{NH}_{3}}$ refrigerant $\mathrm{NH}_{3}$ and the equilibrium saturation temperature of a mixture $\mathrm{NH}_{3}-\mathrm{NaSCN}$ are given by the Ref. [2, 25]:

$\ln P\left(T, X_{N H_{3}}\right)=A_{p}\left(X_{N H_{3}}\right)+\frac{B_{p}\left(X_{N H_{3}}\right)}{T+273.15}$

Where:

$$
\begin{aligned}
& A_{p}\left(X_{{N H_{3}}_{3}}\right)=15.7266-0.298628 \times X_{N_{3}} \\
& B_{p}\left(X_{N H_{3}}\right)=-2548.65-2621.92 \times\left(1-X_{N H_{3}}\right)^{3}
\end{aligned}
$$

The relationship between temperature, concentration $\mathrm{X}_{\mathrm{NH}_{3}}$ in refrigerant $\mathrm{NH}_{3}$ and the enthalpy is as follows $[2,25]$ :

$$
\begin{aligned}
& h\left(T, X_{\mathrm{NH}_{3}}\right)=A_{h}\left(X_{\mathrm{NH}_{3}}\right)+B_{h}\left(X_{\mathrm{NH}_{3}}\right) \times T+C_{h}\left(X_{\mathrm{NH}_{3}}\right) \\
& \times T^{2}+D_{h}\left(X_{\mathrm{NH}_{3}}\right) \times T^{3}
\end{aligned}
$$

Where:

$$
\begin{aligned}
& A_{h}\left(X_{N_{3}}\right)=79.72-1072 \times X_{N_{3}}+1287.9 \times X_{N H_{3}}^{2} \\
& -295.67 \times X_{N H_{3}}^{3} \\
& B_{h}\left(X_{N_{3}}\right)=2.4081-2.2814 \times X_{N H_{3}}+7.9291 \times X_{N H_{3}}^{2} \\
& -3.5137 \times X_{N H_{3}}^{3} \\
& C_{h}\left(X_{N H_{3}}\right)=10^{-2}\left(1.255 \times X_{N H_{3}}-4 \times X_{N_{3}}^{2}+3.06 \times X_{N H_{3}}^{3}\right) \\
& D_{h}\left(X_{N H_{3}}\right)=10^{-5}\left(-3.33 \times X_{N_{3}}+10 \times X_{N H_{3}}^{2}-3.33 \times X_{N H_{3}}^{3}\right)
\end{aligned}
$$

The density of the solution is related to the concentration $\mathrm{X}_{\mathrm{NH}_{3}}$ in refrigerant $\mathrm{NH}_{3}$ of the binary mixture and the temperature $[2,25]$ :

$$
\rho\left(T, X_{N H_{3}}\right)=A_{\rho}\left(X_{N H_{3}}\right)+B_{\rho}\left(X_{N H_{3}}\right) \times T+C_{\rho}\left(X_{N H_{3}}\right) \times T^{2}
$$

Where:

$$
\begin{aligned}
& A_{\rho}\left(X_{N_{3}}\right)=1707.519-2400.4348 \times X_{N_{3}} \\
& +2256.5083 \times X_{N H_{3}}^{2}-930.0637 \times X_{N H_{3}}^{3}
\end{aligned}
$$

Table 2: Coefficients of Equations (39) - (41)

\begin{tabular}{|c|c|c|c|}
\hline $\mathbf{i}$ & $a_{i}$ equation (39) & $b_{i}$ equation (40) & $c_{i}$ equation (41) \\
\hline \hline 0 & $4.2871 \times 10^{-1}$ & $1.9879 \times 10^{-2}$ & $1.4633 \times 10^{3}$ \\
1 & $1.6001 \times 10^{-2}$ & $4.4644 \times 10^{0}$ & $1.2839 \times 10^{0}$ \\
2 & $2.3652 \times 10^{-4}$ & $2.3652 \times 10^{-4}$ & $-1.1501 \times 10^{-2}$ \\
3 & $1.6132 \times 10^{-6}$ & $6.2790 \times 10^{-3}$ & $-2.1523 \times 10^{-4}$ \\
4 & $2.4303 \times 10^{-9}$ & $1.4591 \times 10^{-4}$ & $1.9055 \times 10^{-6}$ \\
6 & $-1.2494 \times 10^{-11}$ & $-1.5262 \times 10^{-6}$ & $2.5608 \times 10^{-8}$ \\
\end{tabular}


$B_{\rho}\left(X_{N_{3}}\right)=-3.6341 \times X_{N_{3}}+5.4552 \times X_{N_{3}}^{2}$

$-3.1674 \times X_{\mathrm{NH}_{3}}^{3}$

$C_{\rho}\left(X_{N H_{3}}\right)=10^{-2}\left(5.1 \times X_{N_{3}}-3.6 \times X_{N_{3}}^{2}-5.4 \times X_{N H_{3}}^{3}\right)$

The specific heat data for the binary mixture was taken from the work of $\mathrm{NH}_{3}-\mathrm{NaSCN}$ CITATION GuJ VI 1036 [25].

$C_{p}\left(T, X_{N_{3}}\right)=A_{C p}\left(X_{N_{3}}\right)+B_{C p}\left(X_{N_{3}}\right) \times T+C_{C p}\left(X_{N H_{3}}\right) \times T^{2}$

Where:

$A_{C p}\left(X_{N_{3}}\right)=0.24081-0.22814 \times X_{N_{3}}$

$+0.79291 \times X_{\mathrm{NH}_{3}}^{2}-0.35137 \times X_{\mathrm{NH}_{3}}^{3}$

$B_{C p}\left(X_{N H_{3}}\right)=10^{-1}\left(0.251 \times X_{N_{3}}-0.8 \times X_{N H_{3}}^{2}+0.612 \times X_{N H_{3}}^{3}\right)$

$C_{C_{p}}\left(X_{N_{3}}\right)=10^{-3}\left(-0.1 \times X_{N H_{3}}+0.3 \times X_{N H_{3}}^{2}-0.1 \times X_{N H_{3}}^{3}\right)$

\section{SIMULATION PROTOCOL}

The simulation protocol consists of plotting the study and reference curves. For the case of study curves, a program is developed, based on the equations formulated from (1) - (57) and is simulated in the Matlab 2015a environment. The input data is taken in accordance with the work of the Ref. [2]. With a view to extending analyzes, the upper limit of the generator temperature is taken equal to the critical ammonia temperature $\operatorname{Tcr}\left(\mathrm{NH}_{3}\right)=132.4^{\circ} \mathrm{C} \quad$ [26]. The data declared at the start of the program allow the calculation of the thermodynamic parameters at the different points of the cycle, more particularly at points (6) and (8); among which we list the mass flow rates $(\dot{m})$ and the mass heats $\left(C_{p}\right)$. Knowledge of these two thermodynamic parameters at these two points allows the calculation of their respective heat flows $\left(\dot{q}_{c}\right)$. A comparison of the difference of the two heat flows (diff $=\dot{q}_{w s}-\dot{q}_{s s}$ ) from zero is made in order to determine the temperature ranges where the weak solution $($ diff $<0)$ and the strong solution $($ diff $>0)$ govern the heat transfer. The Matlab command $\ll$ find $\gg$ is used for the extraction of negative (the weak solution governs the heat transfer) and positive (the strong solution governs the heat transfer) values to which the corresponding temperature ranges are respectively assigned, depending on whether they are 'act of the generator, the condenser, the evaporator or the absorber. For each temperature range defined, a reset in terms of inlet temperatures is carried out to take into account the thermal behavior of the heat recovery exchanger, materialized by the thermal cooling efficiency in the case where the strong solution governs heat transfer and by thermal heating efficiency in the event that the weak solution governs the heat transfer. The different corresponding curves are plotted by the following.

For the case of reference curves, digitization of the curves of the Ref. [2] is made for the curves of the coefficient of performance and the rate of circulation relative to the binary couple $\mathrm{NH}_{3}-\mathrm{NaSCN}$. The digitization is made from getting Data Graph Digitizer software version 2.26.0.20. This software package is a program for digitizing graphics, plots and maps. It takes into account graphic formats of the JPED type. It allows an easy reorganization of the points of a graph and an export of the data in XLS format. The Microsoft Excel 2010 Excel spreadsheet was used to store the data generated for the purpose of later importing them into the Matlab environment where the plotting of the curves followed. Figure 4 thus summarizes the whole of the simulation protocol used.

\section{VALIDATION OF THE SIMULATION PROGRAM}

The validation of our program consisted of implementing the constant input data from [2] into our program and comparing the results; the results of the Ref. [2] being considered as references. The expression of the thermal efficiency of the heat recovery exchanger was taken as indicated by the Ref. [2]. For the indicated range of generator temperatures $\left[55^{\circ} \mathrm{C}, 105^{\circ} \mathrm{C}\right.$ ] the curves of Figures 5 and 6 have been plotted.

Figures 5 and 6 respectively represent the evolution of the coefficient of performance (COP) and of the circulation rate $\tau(\%)$ of the system as a function of the increase in the temperature of the generator $T_{g}\left({ }^{\circ} \mathrm{C}\right)$. A first observation has been made. For the case of the two figures, the curves of COP and $\tau$ of keeping the same evolution profile. Nevertheless, differences are observed between the study curves and the reference curves.

Table 3 presents the order of magnitude of the relative differences between the thermodynamic properties obtained at different points of the cycle. The Table 4 shows the order of magnitude of the relative differences between the energy flows at the level of the various components of the system. In general, the relative deviations observed are less than $1 \%$. We can therefore attribute the offset of the study curves and the reference curves to the simulation environments used to obtain the different results.

The second observation made is the existence of asymptotic lines for the case of study curves. These 


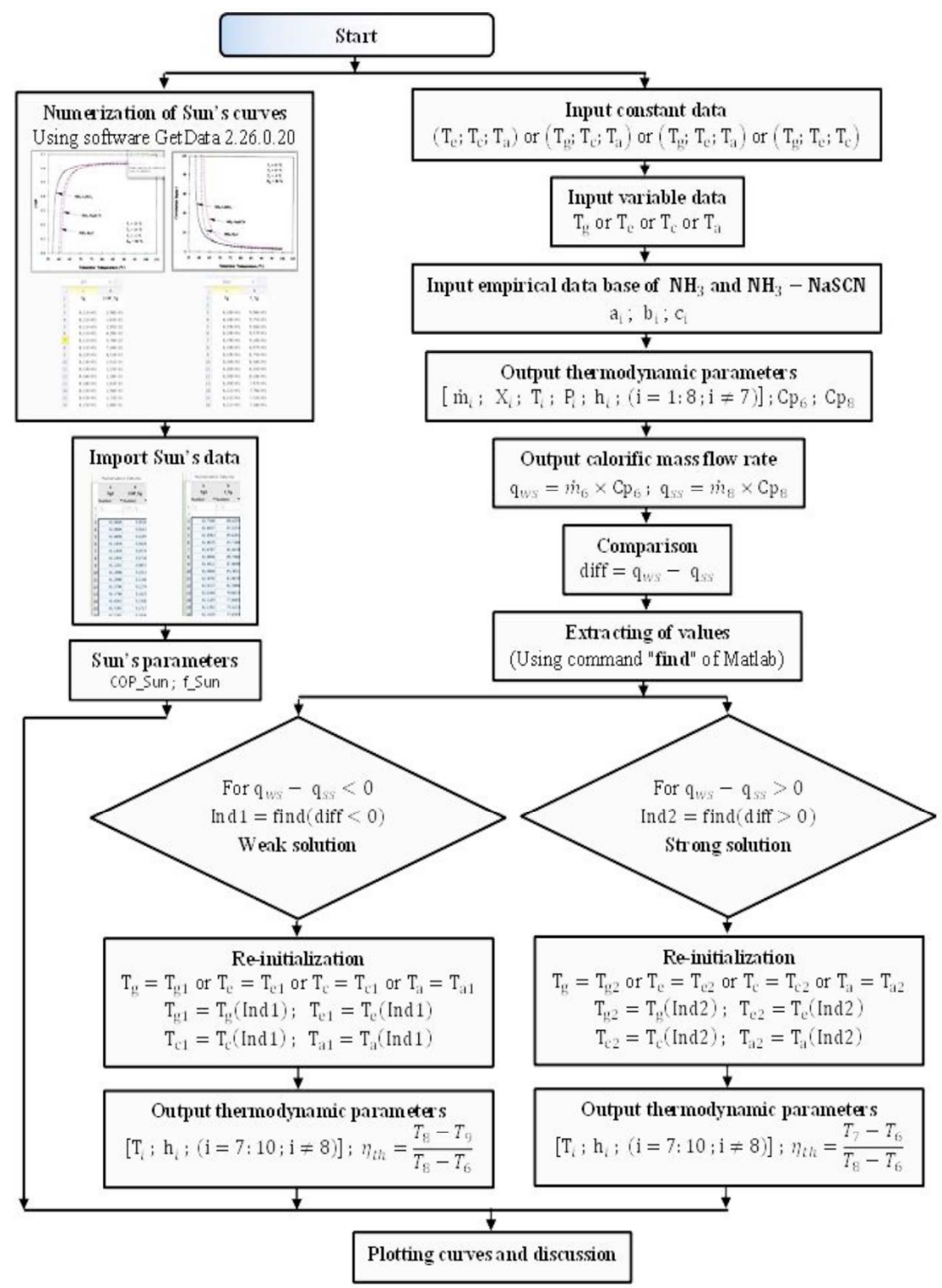

Figure 4: Calculation procedure of optimal operating parameters.

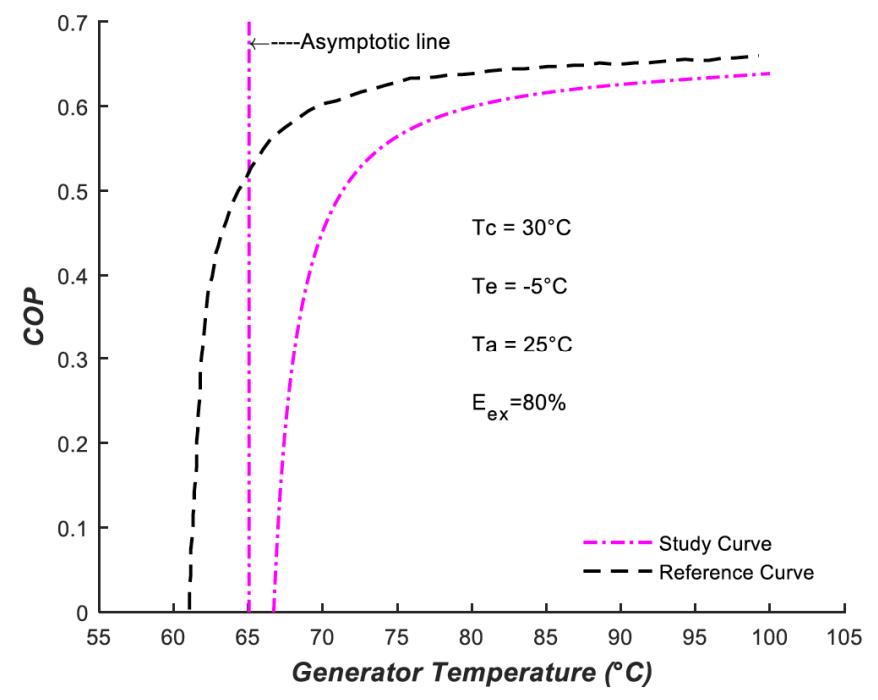

Figure 5: Plot of the COP according to Tg. 


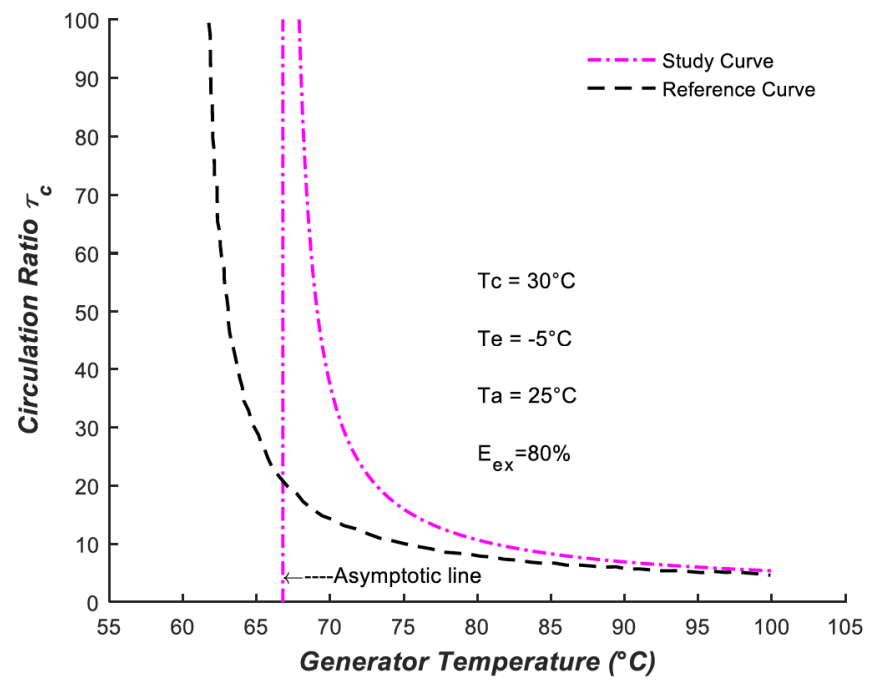

Figure 6: Plot of the Circulation Ration according to Tg.

Table 3: Thermodynamics Properties at Various States in Ammonia-Sodium Thiocyanate Cycle

\begin{tabular}{|c|c|c|c|c|c|c|c|c|c|c|c|c|c|c|c|}
\hline \multirow{2}{*}{$\begin{array}{l}\text { Fluid } \\
\text { state }\end{array}$} & \multicolumn{2}{|c|}{$T\left({ }^{\circ} \mathrm{C}\right)$} & \multirow{2}{*}{$\begin{array}{l}\text { Rel. } \\
\text { error } \\
(\%)\end{array}$} & \multicolumn{2}{|c|}{$P(k P a)$} & \multirow{2}{*}{$\begin{array}{c}\text { Rel. } \\
\text { error } \\
(\%)\end{array}$} & \multicolumn{2}{|c|}{$X(\%)$} & \multirow{2}{*}{$\begin{array}{c}\text { Rel. } \\
\text { error } \\
(\%)\end{array}$} & \multicolumn{2}{|c|}{$m(k g / m i n)$} & \multirow{2}{*}{$\begin{array}{l}\text { Rel. } \\
\text { error } \\
(\%)\end{array}$} & \multicolumn{2}{|c|}{$h(\mathrm{~kJ} / \mathrm{kg})$} & \multirow{2}{*}{$\begin{array}{c}\text { Rel. } \\
\text { error } \\
\text { (\%) }\end{array}$} \\
\hline & $\begin{array}{c}\text { Ref. } \\
\text { states }\end{array}$ & $\begin{array}{l}\text { Study } \\
\text { states }\end{array}$ & & $\begin{array}{c}\text { Ref. } \\
\text { states }\end{array}$ & $\begin{array}{l}\text { Study } \\
\text { states }\end{array}$ & & $\begin{array}{c}\text { Ref. } \\
\text { states }\end{array}$ & $\begin{array}{l}\text { Study } \\
\text { states }\end{array}$ & & $\begin{array}{c}\text { Ref. } \\
\text { states }\end{array}$ & $\begin{array}{l}\text { Study } \\
\text { states }\end{array}$ & & $\begin{array}{c}\text { Ref. } \\
\text { states }\end{array}$ & $\begin{array}{l}\text { Study } \\
\text { states }\end{array}$ & \\
\hline (1) & 100.00 & 100.00 & 0.00 & 1166.92 & 1166.92 & 0.00 & 100.00 & 100.00 & 0.00 & 1.00 & 1.00 & 0.00 & 1448.44 & 1448.44 & 0.00 \\
\hline (2) & 30.00 & 30.00 & 0.00 & 1166.92 & 1166.92 & 0.00 & 100.00 & 100.00 & 0.00 & 1.00 & 1.00 & 0.00 & 340.78 & 340.78 & 0.00 \\
\hline (3) & I & -5.00 & 1 & I & 354.42 & 1 & 1 & 100.00 & 1 & I & 1.00 & I & I & 340.78 & 1 \\
\hline (4) & -5.00 & -5.00 & 0.00 & 354.42 & 354.42 & 0.00 & 100.00 & 100.00 & 0.00 & 1.00 & 1.00 & 0.00 & 1456.62 & 1456.62 & 0.00 \\
\hline (5) & 25.00 & 25.00 & 0.00 & 354.42 & 354.42 & 0.00 & 49.12 & 49.08 & 0.081 & 5.35 & 5.37 & 0.374 & -101.40 & -101.42 & 0.02 \\
\hline (6) & I & 25.31 & I & I & 1166.92 & 1 & I & 49.08 & 1 & I & 5.37 & I & I & -100.56 & 1 \\
\hline (7) & 69.60 & 69.84 & 0.345 & 1166.92 & 1166.92 & 0.00 & 49.12 & 49.08 & 0.081 & 5.35 & 5.37 & 0.374 & 25.13 & 25.20 & 0.29 \\
\hline (8) & 100.00 & 100.00 & 0.00 & 1166.92 & 1166.92 & 0.00 & 37.43 & 37.41 & 0.053 & 4.35 & 4.37 & 0.460 & 98.26 & 98.27 & 0.01 \\
\hline (9) & 1 & 40.25 & 1 & 1 & 1166.92 & 1 & 1 & 37.41 & 1 & I & 4.37 & 1 & I & -55.61 & 1 \\
\hline (10) & 40.00 & 40.25 & 0.625 & 354.42 & 354.42 & 0.00 & 37.43 & 37.41 & 0.053 & 4.35 & 4.37 & 0.460 & -56.27 & -55.61 & 1.17 \\
\hline
\end{tabular}

The number in brackets are shown in Figure 1

I: Unspecified values; Rel.: Relative; Ref.: Reference.

Table 4: Energy Flow each Component in Ammonia-Sodium Thiocyanate Cycle

\begin{tabular}{|c|c|c|c|}
\hline Energy flow & Ref. data & Study data & Relative error (\%) \\
\hline Generator Qg (kW) & 29.0292 & 29.0381 & 0.031 \\
\hline Condenser Qc (kW) & 18.4611 & 18.4611 & 0.000 \\
\hline Evaporator Qe (kW) & 18.5974 & 18.5974 & 0.000 \\
\hline Absorber Qa (kW) & 29.2425 & 29.3007 & 0.199 \\
\hline Pump Wme (kW) & 0.0770 & 0.0770 & 0.000 \\
\hline Recovery Qex (kW) & 11.2151 & 11.2473 & 0.287 \\
\hline COP & 0.6390 & 0.6388 & 0.031 \\
\hline
\end{tabular}

curves are materialized by the temperatures of the generator $T g=65^{\circ} \mathrm{C}$ for the case of the COP evolution curve and, $T g=66.9^{\circ} \mathrm{C}$ in the case of the evolution of the system circulation rate. Table $\mathbf{5}$ was constructed to demonstrate the origin of these different asymptotes from the signs of the mass flow rates at the different 
Table 5: Signs of the Different Thermodynamic Parameters at the Points of the Cycle According to the Ranges of Tg

\begin{tabular}{|c|c|c|c|c|c|c|c|c|c|c|c|}
\hline & Points & 1 & 2 & 3 & 4 & 5 & 6 & 7 & 8 & 9 & 10 \\
\hline $\begin{array}{l}\text { Thermodynamic } \\
\text { parameters }\end{array}$ & $\operatorname{Tg}\left({ }^{\circ} \mathrm{C}\right)$ & & & & & & & & & & \\
\hline \multirow{4}{*}{$\begin{array}{c}\dot{m} \\
(k g / \min )\end{array}$} & {$[55 \cdots 58]$} & + & + & + & + & + & + & + & - & - & - \\
\hline & {$[59 \cdots 63]$} & + & + & + & + & + & + & + & - & - & - \\
\hline & {$[64 \cdots 66]$} & + & + & + & + & + & + & + & - & - & - \\
\hline & {$[67 \cdots 105]$} & + & + & + & + & + & + & + & + & + & + \\
\hline & \multicolumn{11}{|c|}{ : Anormal phenomena } \\
\hline
\end{tabular}

points of the cycle for the temperature range considered. It is observed that for the temperature range $\left(55{ }^{\circ} \mathrm{C}, 66{ }^{\circ} \mathrm{C}\right)$, the mass flow rates of the strong solution at points 8,9 and 10 of the cycle are negative. This observation shows that there are temperature ranges for which the operation of the system makes no physical sense. In the qualitative approach of all the operating equations of the system.

The third observation highlights the so-called starting temperature of the system. The term "start-up temperature" is understood to mean the temperature above which the operation of the system has a physical meaning. It is approximately observed at $61.1^{\circ} \mathrm{C}$ for the reference curves and at $66.9{ }^{\circ} \mathrm{C}$ for the study curves. As a result, it is noted that it is impossible to operate an absorption refrigeration cycle for a generator temperature strictly below $67{ }^{\circ} \mathrm{C}$, a value considered as the starting temperature of the system.

Ultimately, the relative deviations observed of less than $1 \%$ show that the results obtained from our study are weakly influenced and are very close to the reference results. They can therefore be considered as analysis data in the remainder of the study.

\section{RESULTS AND DISCUSSIONS}

Figure 7 is a representation of the change in the COP of the absorption machine as a function of the temperature of the generator relative to the $\mathrm{NH}_{3}-\mathrm{NaSCN}$ binary pair. Three domains limited by two lines $\mathrm{Tg}=66.9{ }^{\circ} \mathrm{C}$ and $\mathrm{Tg}=123.1{ }^{\circ} \mathrm{C}$ are observed. These two delimitation lines represent the temperature limits of the generator for which the thermal operation of the heat recovery exchanger changes depending on the magnitude of the heat flow rates of the weak and strong solutions involved in the heat transfer.

The first area qualified as "non-functional area", within the framework of our study, is materialized by temperatures strictly lower than $66.9^{\circ} \mathrm{C}$ for which the operation of the machine has no positive effect for the function it must perform such as described from Table 5. This is one of the areas where the strong solution governs heat transfer. In this area, we can see part of the curve of the Ref. [2] where the machine is operational from $61.1^{\circ} \mathrm{C}$.

The second domain materialized by the temperature range $\left(66.9{ }^{\circ} \mathrm{C}, 123.1{ }^{\circ} \mathrm{C}\right)$ is that for which the weak solution governs the heat transfer. The heat output of the weak solution is lower than the heat output of the strong solution. The thermal efficiency of the heat recovery exchanger used in this field is "heating efficiency". For this area, we can see that the temperature from which the machine is operational is $66.9^{\circ} \mathrm{C}$, the COP increases strongly between $66.9^{\circ} \mathrm{C}$ and $78.4^{\circ} \mathrm{C}$ and slowly between $78.4^{\circ} \mathrm{C}$ and $123.1^{\circ} \mathrm{C}$ without showing a constant plate.

The third domain materialized by temperatures strictly above $123.1{ }^{\circ} \mathrm{C}$ and limited by the critical ammonia temperature $132.4{ }^{\circ} \mathrm{C}$ [26], is the one for which the strong solution governs the heat transfer. Here, it is the heat flow rate of the strong solution which is lower than the heat flow rate of the weak solution. The thermal efficiency of the heat recovery exchanger used is the "cooling efficiency". In this area, we can see a significant rise in the COP values as a function of the temperature of the generator. This result shows that contrary to the limit indicated by the Ref. [2] for which the operation of absorption cycles with flat plate solar collectors is below $90^{\circ} \mathrm{C}$, it is possible in our case, with a good characterization of the heat recovery exchanger, to reach values of the COP still higher for a generator temperature value close to the critical ammonia temperature. For example, the COP value of 0.87 is reached for a generator temperature of $125^{\circ} \mathrm{C}$; Figure 8 shows that at this value of the generator temperature, the size of the feed pump is much smaller for a power estimated at $0.05 \mathrm{~kW}$. 
There is also continuity between the last two domains. This demonstrates that during the operation of the absorption machine, the change in the thermal behavior of the heat recovery exchanger as a function of the temperature of the generator does not in any way modify the magnitude of the performance of the machine. The last area shows that with the existence of a binary pair as a working fluid capable of withstanding temperatures beyond the critical temperature of ammonia, we could obtain machine performance greater than 1 as in the case of conventional thermodynamic systems (air conditioning, refrigeration). By way of example, with the same operational conditions, the simulation indicates that at $150{ }^{\circ} \mathrm{C}$, a COP value equal to 1.71 and a circulation factor equal to 3.16 corresponding to the working pump of $0.05 \mathrm{~kW}$ were obtained.

Figure 9 is a representation of the values of the COP of the machine evolving as a function of the temperature

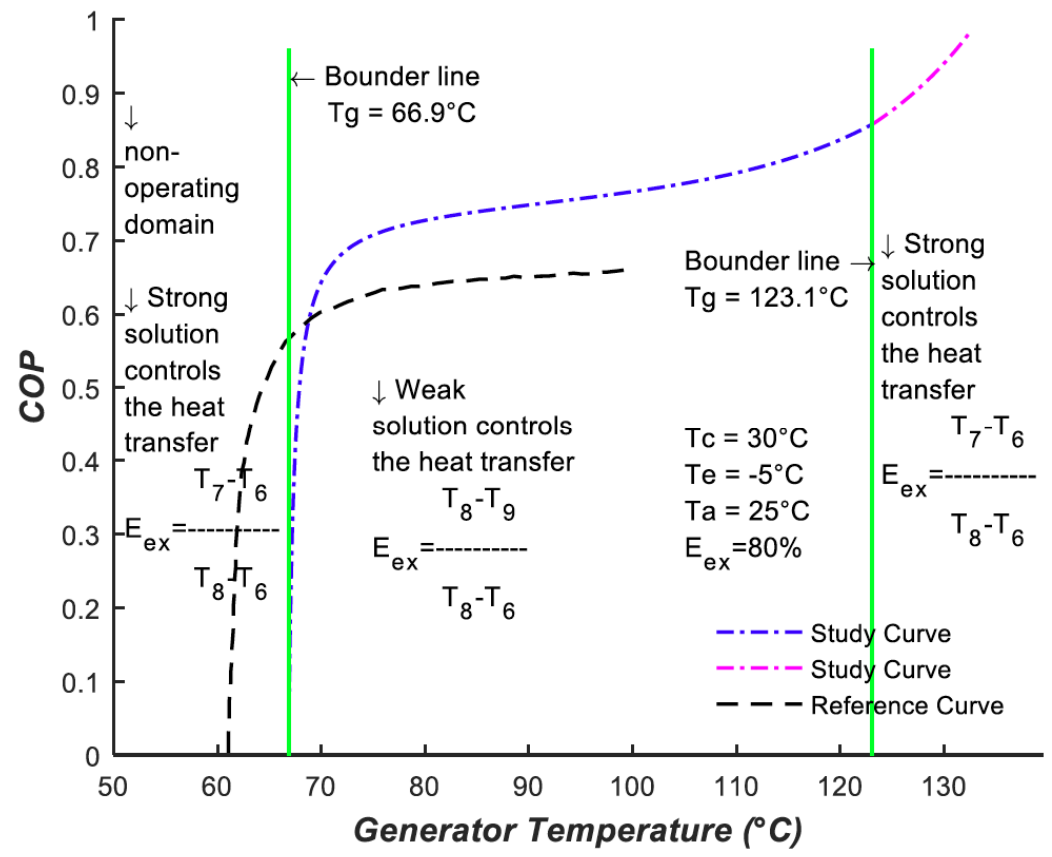

Figure 7: Comparison of the effect of COP values on generator temperatures.

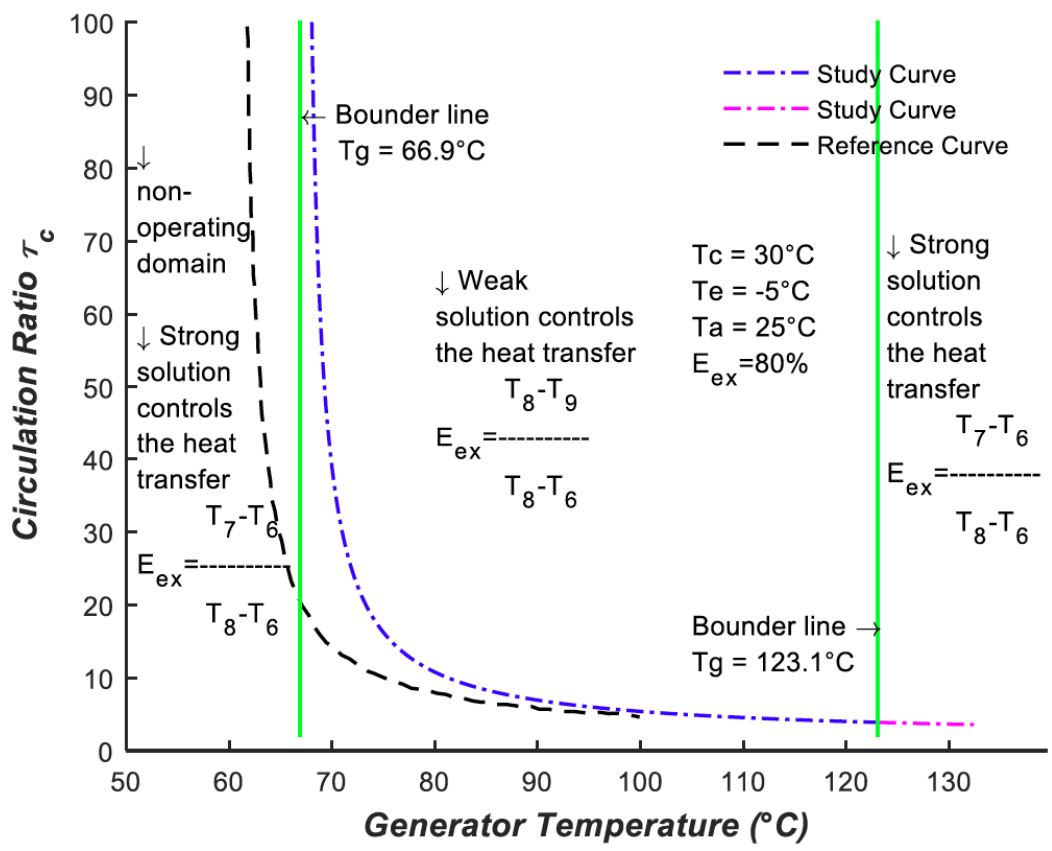

Figure 8: Comparison of the effect of Circulation ratio values on generator temperatures. 
of the evaporator. For the temperature range $\left(-12.5^{\circ} \mathrm{C}\right.$, $12.5{ }^{\circ} \mathrm{C}$ ) considered, two domains are represented limited by two lines $T e=-2.2^{\circ} \mathrm{C}$ and $T e=12.5^{\circ} \mathrm{C}$.

The first domain is materialized by the temperature range $\left(-12.5^{\circ} \mathrm{C},-2.2{ }^{\circ} \mathrm{C}\right)$. In this area, the increase in the temperature of the evaporator has little influence on the increase in the COP of the system. This is characterized by a low slope. But compared to the reference values, the study COP is much better than the reference COP. A similar observation is made for the second domain materialized by the temperature range $\left(-2.2^{\circ} \mathrm{C} 12.5^{\circ} \mathrm{C}\right)$; except that here, the slope of the COP is much more acute. Significant values of the COP are reached up to more than 0.85 . Contrary to [2] where at $-5^{\circ} \mathrm{C}$ we reach values of the COP below 0.65 , we reach in our case, a value of the COP substantially equal to 0.75 at the same temperature; i.e. a gap of $10 \%$.

Figure 10 shows that the thermal behavior of the heat recovery exchanger has no influence on the circulation factor. Whether it is thermal heating efficiency or thermal cooling efficiency, the evolution of the system

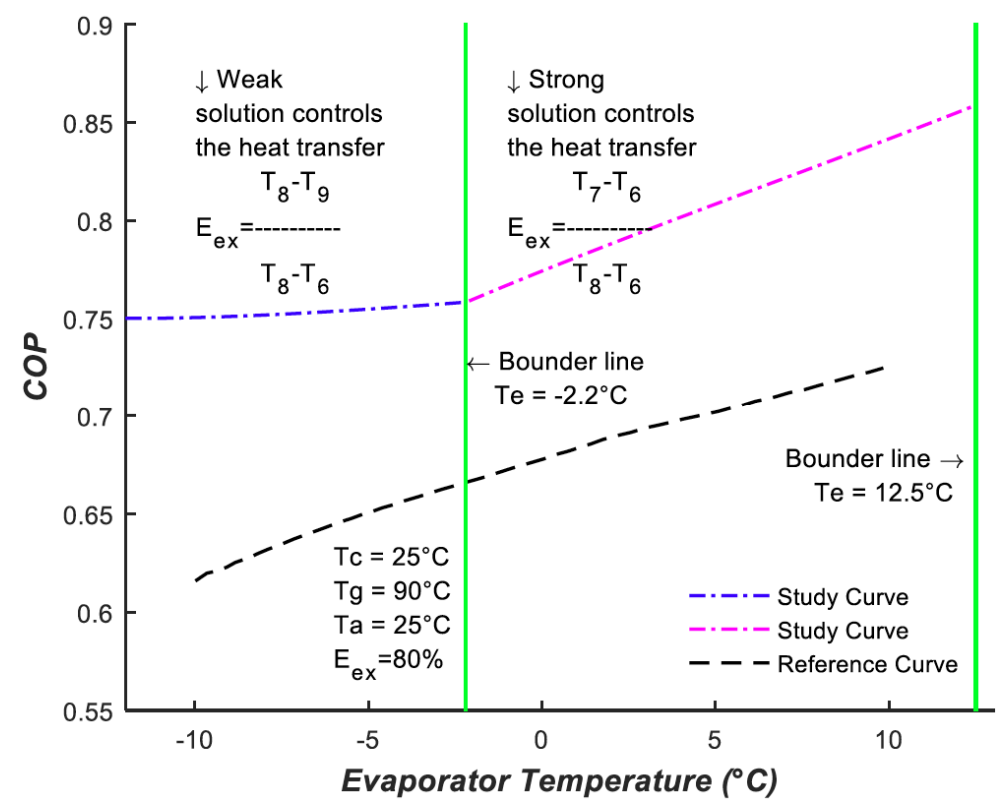

Figure 9: Comparison of the effect of COP values on evaporator temperatures.

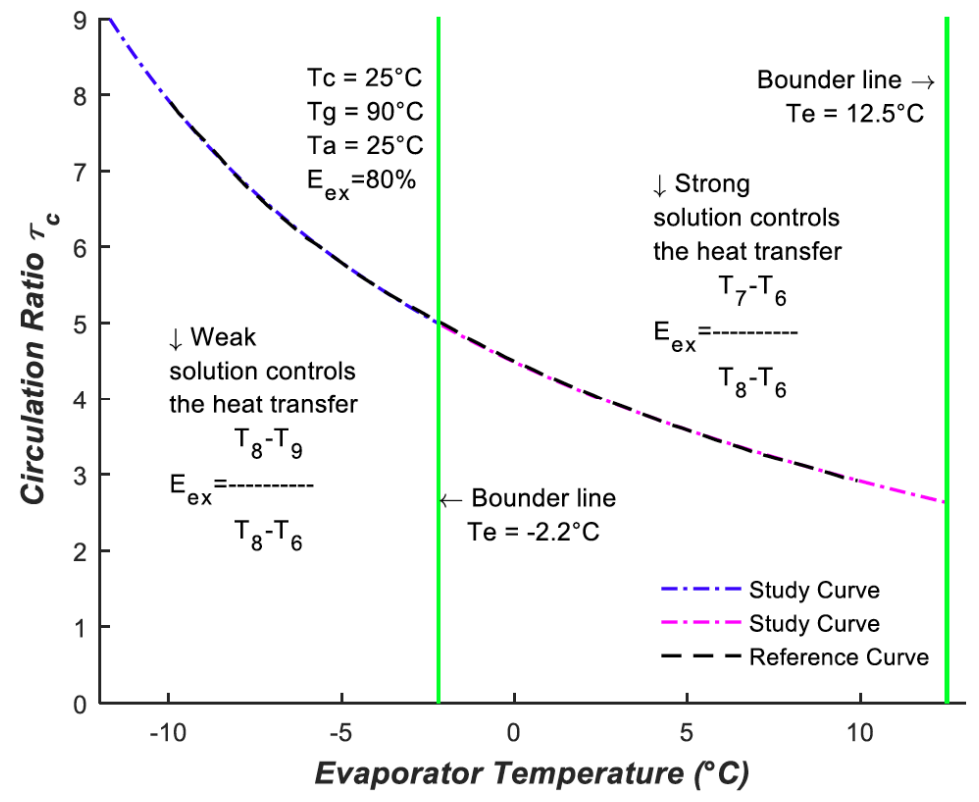

Figure 10: Comparison of the effect of Circulation ratio values on evaporator temperatures. 
circulation rate is continuous and decreases with increasing evaporator temperature.

Figure 11 shows a representation of the values of the COP of the machine changing as a function of the temperature of the condenser. For the temperature range $\left(15{ }^{\circ} \mathrm{C}, 45^{\circ} \mathrm{C}\right)$ considered, two domains are represented limited by the two lines $\mathrm{Tc}=19^{\circ} \mathrm{C}$ and $\mathrm{Tc}$ $=45^{\circ} \mathrm{C}$.

The first domain is materialized by the temperature range $\left(15^{\circ} \mathrm{C}, 19^{\circ} \mathrm{C}\right)$. In this area, the strong solution governs heat transfer. It is observed depending on the set operating conditions, the COP decreases appreciably with the increase in the temperature of the condenser. It is 0.78 at $15{ }^{\circ} \mathrm{C}$ and 0.77 at $19{ }^{\circ} \mathrm{C}$. This area requires the use of a high power condenser. For example, for a condensing temperature of $16{ }^{\circ} \mathrm{C}$, you would need a condenser with a power equal to 19.83 $\mathrm{kW}$. At this same temperature, Figure 12 shows a circulation pump of $0.04 \mathrm{~kW}$ corresponding to a system circulation rate of 4.72 .

In the second domain materialized by the temperature range of the condenser $\left(19{ }^{\circ} \mathrm{C}, 45^{\circ} \mathrm{C}\right)$, the weak solution governs the heat transfer. Two subdomains

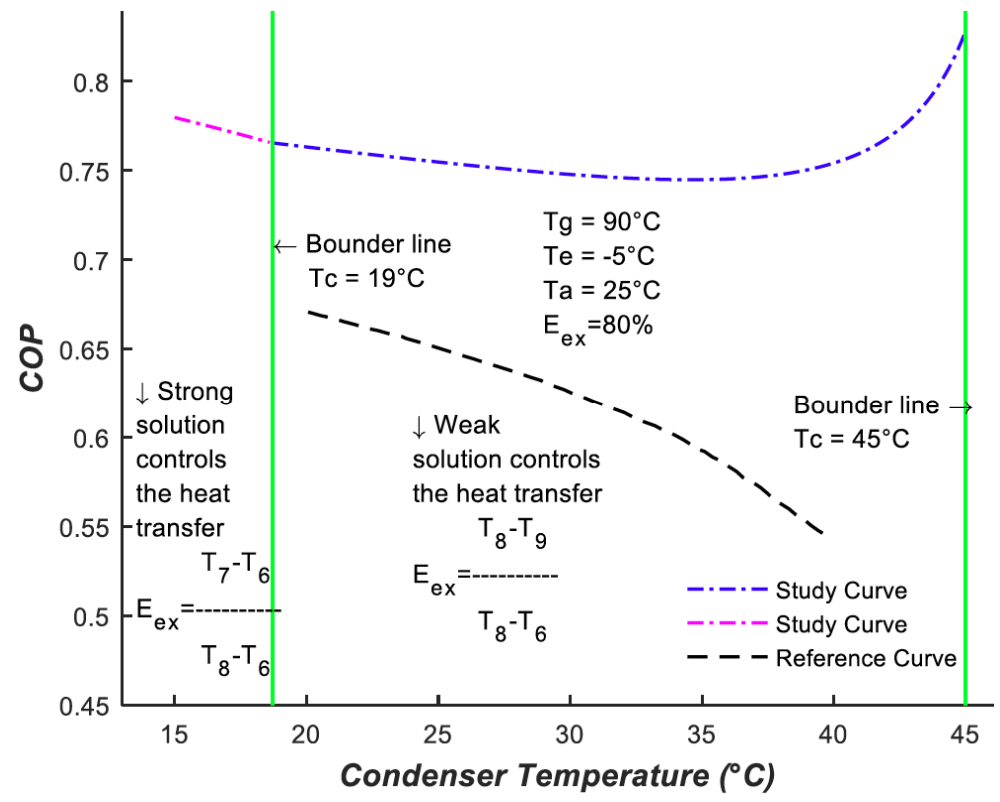

Figure 11: Comparison of the effect of COP values on condenser temperatures.

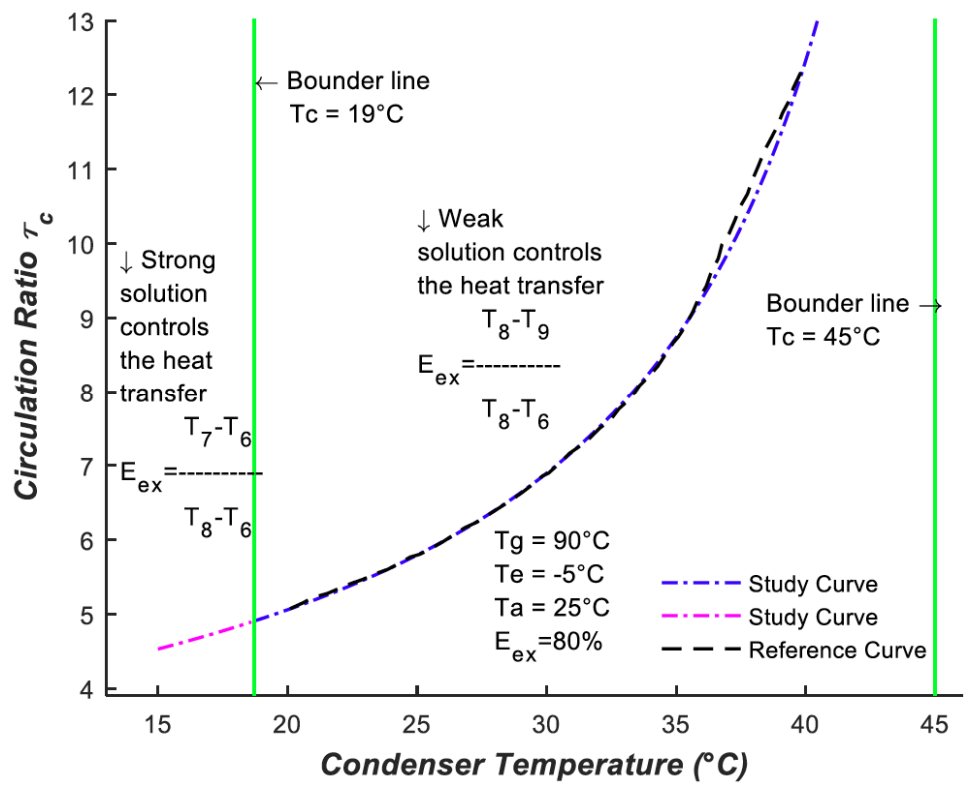

Figure 12: Comparison of the effect of Circulation ratio values on condenser temperatures. 
are to be observed. The first subdomain is defined for condenser temperatures between $19{ }^{\circ} \mathrm{C}$ and $34.6{ }^{\circ} \mathrm{C}$. In this temperature range, the COP decreases little noticeably with the increase in the temperature of the condenser which is characterized by a low slope. Between the temperatures of $34.6{ }^{\circ} \mathrm{C}$ and $45{ }^{\circ} \mathrm{C}$ materializing the second subdomain, it is observed an abrupt rise in the values of the COP from 0.74 to 0.83 .

Figure 12 shows that the nature of the solution which governs the heat transfer has no influence on the circulation factor of the system. The study and reference curves merge perfectly.

Figure 13 is a representation of the values of the COP of the machine evolving as a function of the temperature of the absorber. For the temperature range $\left(15^{\circ} \mathrm{C}, 45^{\circ} \mathrm{C}\right)$ considered, two domains are represented limited by the two lines $\mathrm{Ta}=27.6{ }^{\circ} \mathrm{C}$ and $\mathrm{Ta}=45^{\circ} \mathrm{C}$.

The first domain is materialized by the temperature range $\left(15^{\circ} \mathrm{C}, 27.6^{\circ} \mathrm{C}\right)$. In this area, the strong solution

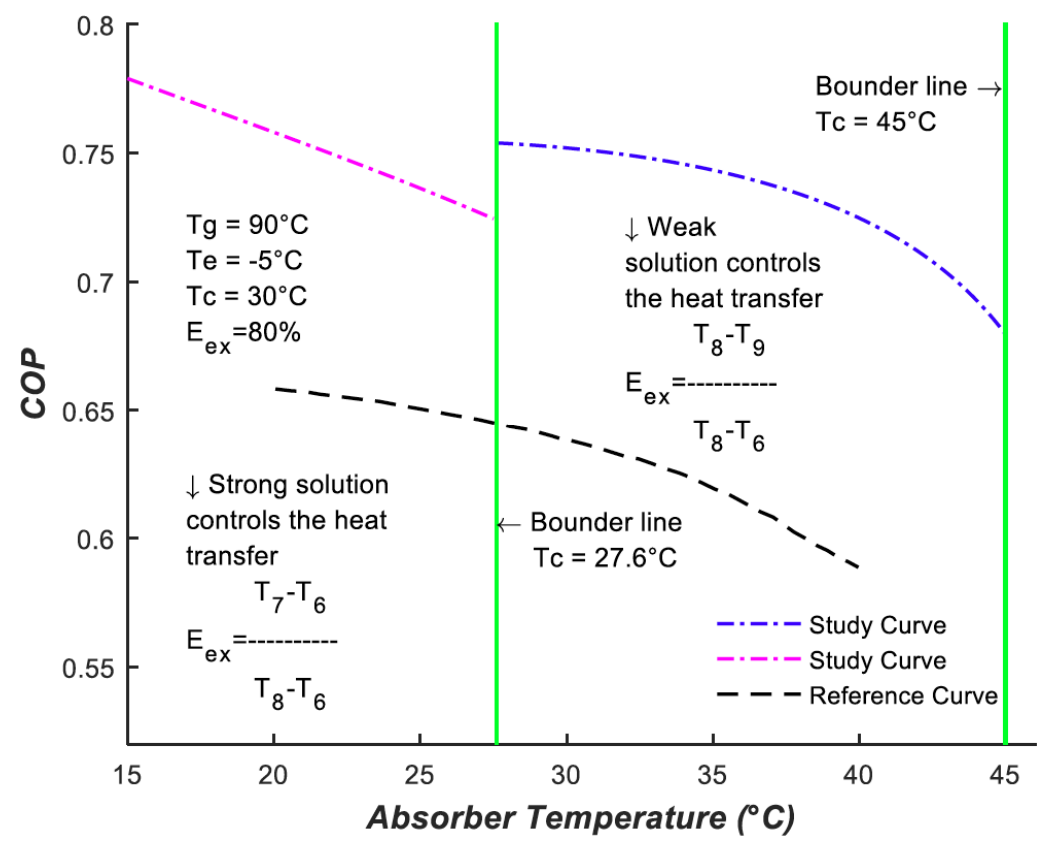

Figure 13: Comparison of the effect of COP values on absorber temperatures.

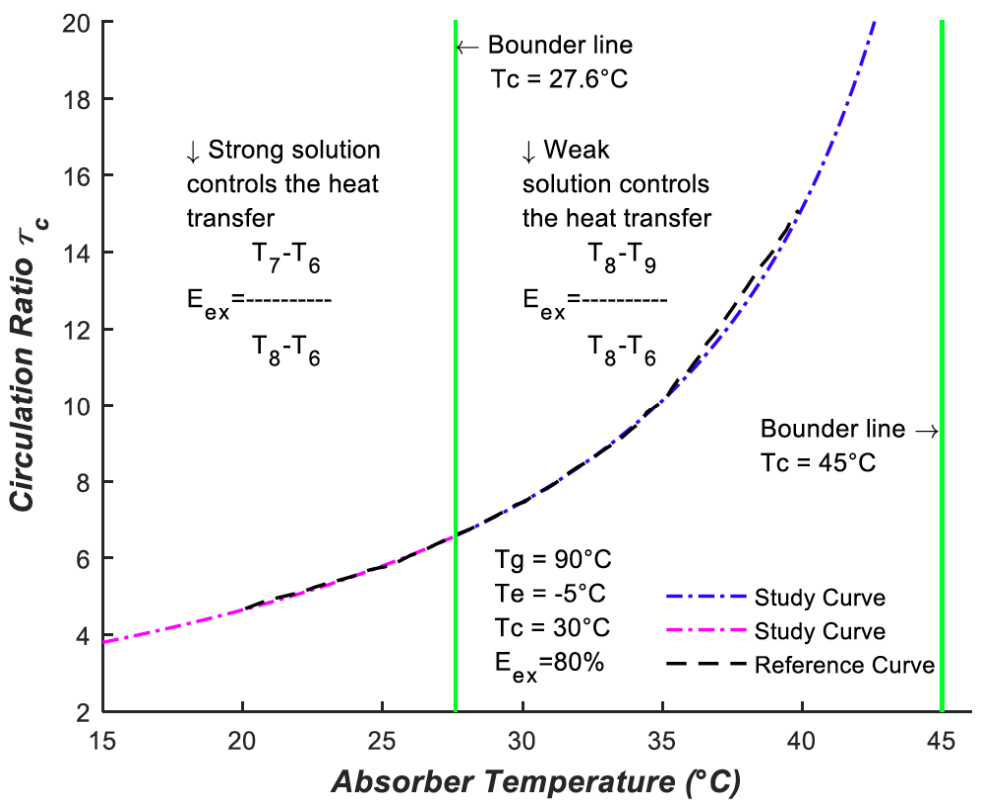

Figure 14: Comparison of the effect of Circulation ratio values on absorber temperatures. 
governs heat transfer. Its heat output is lower than the heat output of the weak solution. It is observed that the values of the COP are quite important for the low temperatures of the absorber. It varies from 0.78 at 15 ${ }^{\circ} \mathrm{C}$ to 0.73 at $27.5^{\circ} \mathrm{C}$.

In the second domain materialized by the temperature range of the condenser $\left(19{ }^{\circ} \mathrm{C}, 45{ }^{\circ} \mathrm{C}\right)$, the weak solution governs the heat transfer. Its heat output is lower than the heat output of the strong solution. The performance of the machine decreases as the temperature of the absorber increases. A discontinuity between the two domains is observed. Figure 14 shows that with regard to the evolution of the circulation rate, this evolution is not influenced by the thermal behavior of the heat recovery exchanger. The study and reference curves overlap perfectly.

\section{CONCLUSION}

Absorption machines have demonstrated their positive impact on the valorization of renewable energies and, in part, in the protection of the environment. Providing a precise energy analysis to these machines would make it possible to optimize both their performance and the size of their equipment. Carrying out a study on the thermal behavior of the heat recovery exchanger regularly used, the results obtained showed that the performances of the absorption machine strongly depend on the thermal behavior of the heat recovery exchanger. In other words, depending on certain temperature ranges, the weak solution or the strong solution governs the heat transfer; which gives rise respectively to the cooling and heating efficiencies. Taking into account these two types of efficiency, it was found that the performance of the machine is even more important and the size of its equipment reduced. Also, it has been shown that it is possible to operate with generator temperatures above $90{ }^{\circ} \mathrm{C}$. and close to the critical ammonia temperature. Since the thermal behavior of the heat recovery exchanger does not influence the value of the coefficient of performance in any way, it has been observed that it is possible to obtain values strictly beyond 1 if it was possible to have a working fluid capable of withstanding temperatures above $150^{\circ} \mathrm{C}$.

\section{REFERENCES}

[1] Cerezo J, Best R, Romero RJ. A study of a bubble absorber using a plate heat exchanger with $\mathrm{NH} 3-\mathrm{H} 2 \mathrm{O}$, NH3-LiNO3 and NH-NaSCN. Applied Thermal Engineering 2011; 31: 1869-1876.

https://doi.org/10.1016/j.applthermaleng.2011.02.032
Sun D-W. Comparison of the performance of $\mathrm{NH} 3-\mathrm{H} 2 \mathrm{O}$, NHLiNO3 and NH3-NaSCN absorption refrigeration systems. Energy Conversion and Management 1998; 39: 357-368. https://doi.org/10.1016/S0196-8904(97)00027-7

[3] Fayad S, Younes R, Abboudi S. Numerical Simulation of Solar Absorption Machine. Energy Procedia 2011; 6: 130135.

https://doi.org/10.1016/j.egypro.2011.05.015

[4] Zhu L, Gu J. Second Law-based thermodynamic analysis of ammonia/sodium thiocyanate absorption system. Renewable Energy 2010; 35: 1940-1946. https://doi.org/10.1016/j.renene.2010.01.022

[5] Cui P, Yu M, Liu Z, Zhu Z, Yang S. Energy, exergy, and economic (3E) analyses and multi-objective optimization of a cascade absorption refrigeration system for law-grade waste heat recovery. Energy Conversion and Management 2019; 184: 249-261. https://doi.org/10.1016/j.enconman.2019.01.047

[6] Xu Q, Lu D, Chen G, Guo H, Dong X, Zhao Y. Experimental study on an absorption refrigeration system driven by temperature-distributed heat sources. Energy 2019; 170: 471-479.

https://doi.org/10.1016/j.energy.2018.12.159

[7] Acuna A, Velazquez N, Cerezo J. Energy analysis of a diffusion absorption cooling system using lithium nitrate, sodium thiocyanate and water as absorbent substances and ammonia as the refrigerant. Applied Thermal Engineering 2013; 51: 1273-1281.

https://doi.org/10.1016/j.applthermaleng.2012.10.046

[8] Garousi Farshi L, Mosaffa AH, Infante Ferreira CA, Rosen MA. Thermodynamic analysis and comparison of combined ejector-absorption and single effect absorption refrigeration systems. Applied Energy 2014; 133: 335-346. https://doi.org/10.1016/j.apenergy.2014.07.102

[9] Safarnezhad Bagheri B, Shirmohammadi R, Seyed Mahmoudi SM, Rosen MA. Optimization and comprehensive exergy-based analyses of a parallel flow double-effect waterlithium bromide absorption refrigeration system. Applied Thermal Engineering 2019.

https://doi.org/10.1016/j.applthermaleng.2019.02.105

[10] Nourafkan E, Asachi M, Jin H, Wen D, Ahmed W. Stability and photo-thermal conversion performance of binary nanofluids for solar absorption refrigeration systems. Renewable Energy 2019. https://doi.org/10.1016/j.renene.2019.01.081

[11] Gutiérrez-Urueta G, Rodriguez $P$, Venegas M, Ziegler F, Rodriguez-Hidalgo M. Experimental performances of a LiBrwater absorption facility equipped with adiabatic absorber. International Journal or Refrigeration 2011; 34: 1749-1759. https://doi.org/10.1016/j.jirefrig.2011.07.014

[12] Takalkar GD, Bhosale RR, Mali NA, Bhagwat SS Thermodynamic Analysis of EMISE-Water as a Working Pair for Absorption Refrigeration System. Applied Thermal Engineering 2018. https://doi.org/10.1016/j.applthermaleng.2018.11.092

[13] Bourseau $P$, Bugarel R. Réfrigération par cycle à absorptiondiffusion: comparaison des performances des $\mathrm{NH} 3-\mathrm{H} 2 \mathrm{O}$ et NH3-NaSCN. Int J Refrig 1986; 9. https://doi.org/10.1016/0140-7007(86)90092-7

[14] Jannot Y. Transferts Thermiques. Ecole des Mines Nancy, 2ème Année 2012.

[15] Abdulateef JM, Sopian K, Alghoul MA, Sulaiman MA, Zaharim A, Ahmad I. Solar Absorption Refrigeration System Using New Working Fluid Pairs. International Journal of Energy 2007; 3(1).

[16] Razmi A, Soltani M, Aghanajafi C, Torabi M. Thermodynamic and economic investigation of a novel integration of the absorption-recompression refrigeration system with 
compressed air energy storage (CAES). Energy Conversion and Management 2019; 187: 262-273.

https://doi.org/10.1016/j.enconman.2019.03.010

[17] Liu X, Ye Z, Bai L, He M. Performance comparaison of two absorption-compression hybrid refrigeration systems using R1234yf/ionic liquid as working pair. Energy Conversion and Management 2019; 181: 319-330.

https://doi.org/10.1016/j.enconman.2018.12.030

[18] Bellos E, Chatzovoulos I, Tzivanidis C. Yearly investigation of a solar-drven absorption refrigeration system with ammoniawater absorption pair. Thermal Science and Engineering Progress 2021; 23: 100885.

https://doi.org/10.1016/j.tsep.2021.100885

[19] Cai D, He G, Tian Q, Bian Y, Xiao R, Zhang A. First law analysis of a novel double effect air-cooled non-adiabatic ammonia/salt absorption refrigeration cycle. Energy Conversion and Management 2015; 98: 1-14. https://doi.org/10.1016/j.enconman.2015.03.083

[20] Chaudhari K, Salavera D, Coronas A. Densities, Viscosities, Heat Capacities, and Vapor-Liquid Equilibria of Ammonia + Sodium Thiocyanate Solutions at the Several Temperatures. Journal of Chemical \& Engineering Data 2011; 56: 26812869.

https://doi.org/10.1021/je200038n
[21] Golasi I, Salata F, Vollaro EL, Coppi M. The degradation of ammonia in absorption thermal machines. Energy Procedia 2017; 126: 321-328.

https://doi.org/10.1016/j.egypro.2017.08.252

[22] Infante Ferreira CA. Thermodynamic and Physical Property Data Equations for Ammonia-Lithium Nitrate and AmmoniaSodium Thiocyanate Solutions. Solar Energy 1984; 32: 231236.

https://doi.org/10.1016/S0038-092X(84)80040-7

[23] Blytas GC, Daniels F. Concentrated Solutions of NaSCN in Liquid Ammonia. Solubility, Density, Vapor Pressure, Viscosity, Thermal Conductance, Heat of Solution and Heat Capacity. Journal of the American Chemical Society 1962; 84 https://doi.org/10.1021/ja00866a001

[24] American Society of Heating Refrigerating and Airconditionning Engineers, ASHRAE Handbook Fundamentals, Atlanta 2009

[25] Gu J, Gan Z. Entransy in Phase-Change Systems, Springer Briefs in Applied Sciences and Technology. Thermal Engineering and Applied Science 2014.

https://doi.org/10.1007/978-3-319-07428-3

[26] Cengel YA, Boles MA, Lacroix M. Thermodynamique: Une Approche Pragmatique. Les Editions de la Chenelière Inc. 2008. 